\title{
Adrenomedullin increases fibroblast-like synoviocyte adhesion to extracellular matrix proteins by upregulating integrin activation
}

\author{
Marie-Dominique Ah Kioon ${ }^{1,2}$, Carine Asensio ${ }^{1,2}$, Hang-Korng Ea ${ }^{1,2,3}$, Benjamin Uzan ${ }^{1,2}$, Martine Cohen-Solal ${ }^{1,2,3}$,
} Frédéric Lioté ${ }^{1,2,3^{*}}$

\begin{abstract}
Introduction: Rheumatoid arthritis (RA) is characterized by bone and cartilage invasion by fibroblast-like synoviocytes (FLSs). Adrenomedullin, a peptide with anabolic and antiapoptotic properties, is secreted by rheumatoid FLSs. Adrenomedullin also increases the expression of adhesion molecules in endothelial cells and keratinocytes. Here, we investigated whether adrenomedullin mediated FLS adhesion to extracellular matrix (ECM) proteins.

Methods: FLSs were isolated from synovial tissues from RA and osteoarthritis (OA) patients. Plates were coated overnight with the ECM proteins vitronectin, fibronectin, and type I collagen (Coll.I). Adrenomedullin was used as a soluble FLS ligand before plating. We tested interactions with the adrenomedullin receptor antagonist (22-52) adrenomedullin and with the protein kinase A (PKA) inhibitor $\mathrm{H}-89$, and inhibition of co-receptor RAMP-2 by siRNA. Cell adhesion was measured by using color densitometry. Activation of $\alpha_{2}$ and $\beta_{1}$ integrins was evaluated by fluorescent microscopy; integrin inhibition, by RGD peptides; and the talin-integrin interaction, by immunoprecipitation (IP).
\end{abstract}

Results: Adrenomedullin specifically increased RA-FLS adhesion to vitronectin, fibronectin, and Coll.l; no such effect was found for OA-FLS adhesion. Basal or adrenomedullin-stimulated RA-FLS adhesion was inhibited by (22-52) adrenomedullin, H-89, and RAMP-2 siRNA. Adrenomedullin-stimulated adhesion was inhibited by RGD peptides, and associated with $\alpha_{2}$ and $\beta_{1}$ integrin activation. This activation was shown with IP to be related to an integrintalin interaction and was significantly decreased by (22-52)adrenomedullin.

Conclusions: Adrenomedullin-stimulated RA-FLS adhesion was specific for ECM proteins and mediated by $\alpha_{2}$ and $\beta_{1}$ integrins. This effect of adrenomedullin was dependent on adrenomedullin receptors. These results support a new role for adrenomedullin in rheumatoid synovial fibroblast pathobiology.

\section{Introduction}

Rheumatoid arthritis (RA) is a chronic inflammatory joint disease in which fibroblast-like synoviocytes (FLSs) invade the extracellular matrix (ECM) of cartilage and bone, causing destruction of both tissues. FLSs in patients with RA (RA-FLSs) differ from normal FLSs regarding both morphologic and biologic characteristics

\footnotetext{
* Correspondence: frederic.liote@lrb.aphp.fr

'INSERM UMR-S 606, Hôpital Lariboisière, Ambroise Paré Street, 75010 Paris, France

Full list of author information is available at the end of the article
}

[1]. More specifically, RA-FLSs can adhere to ECM proteins $[1,2]$ by a number of adhesion molecules.

Among the adhesion molecules expressed by FLSs, integrins interact with several ECM proteins, including collagen, fibronectin, and vitronectin. Integrins are heterodimeric proteins composed of two subunits, $\alpha$ and $\beta$. When integrins bind to their ligands, they undergo activation with conformational changes regulated by inside-out signals [3]. Changes in extracellular domain conformation are initiated by binding of talin to an integ$\operatorname{rin} \beta$ cytoplasmic domain $[4,5]$. Binding of talin to integrin disrupts the salt bridge between the two chains,
Ciomed Central

C 2010 Lioté et al.; licensee BioMed Central Ltd. This is an open access article distributed under the terms of the Creative Commons Attribution License (http://creativecommons.org/licenses/by/2.0), which permits unrestricted use, distribution, and reproduction in any medium, provided the original work is properly cited 
thereby activating the integrin molecule [6]. RA-FLSs overexpress the integrins $\alpha_{1} \beta_{1}, \alpha_{2} \beta_{1}, \alpha_{3} \beta_{1}$, and $\alpha_{v} \beta_{3}$ [7]. The activation and adhesion properties of RA-FLSs may be intrinsic to these cells or related to factors such as cytokines and other molecules produced by RA-FLSs. Adrenomedullin may be one such factor.

Adrenomedullin is a 52-amino acid peptide first identified in 1993 in human pheochromocytoma. This peptide contains two structures important for its activity: a loop of six amino acids formed by a disulfide bond between residues 16 and 21 and an amide bond on the $C$-terminal tyrosine residue [8]. The (22-52)adrenomedullin truncated peptide does not have the six-amino acid ring and can act as an antagonist of the adrenomedullin receptor, depending on the cell type and species. In FLSs, adrenomedullin binds to a heterodimeric plasma membrane receptor composed of the seven-transmembrane domain protein calcitonin receptor-like receptor (CLR) coupled to one of two receptor activity-modifying proteins (RAMP-2 or -3) [9]. CLR signal transduction is mediated through $G$ protein-coupled adenylate cyclase $(A C)$ and protein kinase A (PKA) pathways [10].

Several reports support a role for adrenomedullin in the pathogenesis of RA. Plasma adrenomedullin levels are higher in RA than in other inflammatory diseases (lupus and scleroderma), osteoarthritis (OA), and in normal individuals [11]. Furthermore, adrenomedullin levels in plasma and synovial fluid are higher in RA than in OA [12].

More recently, our group reported overexpression in RA-FLSs of adrenomedullin and its CLR/RAMP-2,3 receptor mRNA and protein, compared with FLSs from OA patients (OA-FLS) [10]. Adrenomedullin was secreted by RA-FLSs and may act as a soluble factor. Indeed, the adrenomedullin receptor was functional, because adrenomedullin stimulation led to intracellular cAMP production and to decreased FLS apoptosis triggered by various conditions through PKA. Moreover, (22-52)adrenomedullin competitively and dose-dependently blocked the antiapoptotic effect of adrenomedullin on RA-FLSs.

Interestingly, adrenomedullin has several other effects, depending on the cell type: it increases cell proliferation [13]; inhibits smooth muscle cell migration [14]; and stimulates human umbilical vein endothelial cell (HUVEC) proliferation and migration [15], as well as angiogenesis in vitro [15] and in vivo [16]. Adrenomedullin also induces the expression of adhesion molecules (intercellular adhesion molecule, or ICAM; and endothelial selectin, or E-selectin) at the surface of HUVECs [17] and human oral keratinocytes [18].

The objective of this study was to determine whether adrenomedullin was involved in the adhesion of RAFLSs to ECM proteins of bone and cartilage.

\section{Materials and methods \\ Synovial specimens}

Synovial tissues were obtained under aseptic conditions from $11 \mathrm{RA}$ and three OA patients undergoing total kneeor hip-replacement surgery or wrist synovectomy. All RA patients fulfilled the 1987 American College of Rheumatology criteria for RA [19], and all OA patients had joint pain with radiologic evidence of degenerative changes at surgery. Disease activity and medications at surgery were not recorded. All human sample-collection procedures complied with the Helsinki Declaration. According to French Law on human research (Law 2007-1110, article 1211-2), synovial sample collection (surgical waste) was authorized unless opposition from patients occurred; all patients were informed.

\section{Primary synovial fibroblast cultures}

Synovial tissues were minced in HAM F-12 culture medium and then incubated overnight at $37^{\circ} \mathrm{C}$ with $1 \mathrm{mg} / \mathrm{ml}$ of type I collagenase (Sigma-Aldrich). After cell dissociation, the samples were filtered through a cell strainer. Cell suspensions and cultures were carried out as previously described [10]. Cell confluence and morphology were assessed throughout the experiments by phase-contrast microscopy, as described elsewhere [20]. All experiments were carried out by using primary synovial cells cultured between passages 3 and 6 .

\section{Reagents}

Human adrenomedullin (1-52) and (22-52)adrenomedullin were purchased from Bachem. PBS, trypsin-EDTA, and HAM F-12 were obtained from Invitrogen Life Technologies. Fetal calf serum (FCS) was from Dutscher; the same batch was used in all experiments. Fibronectin, vitronectin, Coll.I, bovine serum albumin (BSA), RAMP2 siRNA, RGD and scrambled peptides, and the PKA inhibitor H-89 were purchased from Sigma-Aldrich. CD49b $\left(\alpha_{2}\right)$ Fluorescein IsoThioCyanate (FITC)-conjugated antibody, CD29 ( $\beta 1$ ) phycoerythrin (PE)-conjugated antibody, PE Mouse IgG2a, and FITC Mouse IgG1 (isotype controls) were bought from BD Pharmingen. Paraformaldehyde (PFA) was purchased from Panreac.

\section{Adhesion assay}

The wells of 96-well flat-bottomed plates were coated overnight at $4^{\circ} \mathrm{C}$ with $100 \mu \mathrm{l}$ of three ECM proteins, at the following optimal doses defined in preliminary experiments: vitronectin, $0.1 \mu \mathrm{g} / \mathrm{cm}^{2}$; fibronectin, 0.01 $\mu \mathrm{g} / \mathrm{cm}^{2}$; and Coll.I, $0.1 \mu \mathrm{g} / \mathrm{cm}^{2}$. BSA $0.1 \%$ and polylysin $0.1 \mu \mathrm{g} / \mathrm{cm}^{2}$ were used as nonspecific controls. Wells were blocked with $0.1 \%$ BSA for 1 hour at room temperature (RT). Then FLSs previously cultured in HAMF12 10\% FCS were harvested with trypsin-EDTA, 
pelleted, and resuspended in HAM-F12 without FCS but with $\mathrm{Ca}^{2+}$ and $\mathrm{Mg}^{2+}$ to allow integrin activation.

To investigate the effect of adrenomedullin, we incubated FLS at RT for 1 hour with adrenomedullin at indicated concentrations. After washing, $10^{5}$ cells were seeded in each well and incubated for different periods at $37^{\circ} \mathrm{C}$. Each condition was done in quadruplicate. After incubation, unbound cells were removed along with the culture medium. Remaining adherent cells were colored for 15 minutes with $0.5 \%$ violet crystal and fixed with $20 \%$ methanol. Plates were washed twice with $300 \mu$ of PBS 1X, and adherent cells were lysed with 1\% SDS. Adhesion was quantified with spectrophotometric opticdensity measurement at $550 \mathrm{~nm}$ (Dynatech MR5000).

To study the effects of the adrenomedullin receptor antagonist (22-52)AM, of the PKA inhibitor $\mathrm{H}-89$, and of RGD peptide (integrin competitor), FLSs were preincubated with (22-52)AM or $\mathrm{H}-89$ at $10^{-8}, 10^{-7}$, or $10^{-6} \mathrm{M}$, or with RGD (50, 100, $150 \mu \mathrm{g} / \mathrm{ml}$; or scrambled peptide (150 $\mu \mathrm{g} / \mathrm{ml}$ ) as control) for 30 minutes and then treated with adrenomedullin or left untreated for 1 additional hour. The adhesion assay was performed as described earlier.

\section{Small interference RNA}

To silence RAMP-2 expression in RA-FLS, an siRNA, ID number SASI_Hs01_00149404 [EBI:NM_005854], was used. Cells were transfected by using the INTERFERIN transfection reagent (Ozyme) according to the manufacturer's instructions. siRNA was diluted in transfection reagent and culture medium, and cells were incubated with siRNA $(5,10$, and $20 \mathrm{nM})$ for $24 \mathrm{~h}$ before being processed for adhesion assay.

\section{Fluorescence microscopy}

FLSs were incubated for 1 hour with $10^{-7} \mathrm{M}$ adrenomedullin and washed. Then, $10^{5}$ cells were plated on eightwell LabTek uncoated coverslips (Nunc A/S) for 2 hours at $37^{\circ} \mathrm{C}$. After incubation, nonadherent cells were removed along with the culture medium. The cells were fixed with $4 \%$ PFA in PBS. Nonspecific sites were blocked with $3 \%$ BSA in PBS for 1 hour at RT. For immunostaining, cells were incubated for 1 hour with both monoclonal AK-7 $\alpha 2$ - FITC and HUTS-21 $\beta 1$-PE antibodies $(\mathrm{Mc} \mathrm{Ab})$ diluted $1 / 40$ in $3 \% \mathrm{BSA}$. As a negative control, cells were incubated with $\gamma 2$-FITC and $\gamma 1$ $\mathrm{PE}$ isotype control. The nuclei were then stained with DAPI for 5 minutes. Cells were mounted in fluorescent mounting medium (Dako) and viewed by using a fluorescence microscope (Nikon) interfaced with the software package Microvision Instrument.

Where indicated, FLSs were preincubated with $10^{-6} \mathrm{M}$ (22-52)AM for 30 minutes before being treated with adrenomedullin or left untreated for 1 hour and then processed for fluorescence microscopy, as described.

\section{Talin immunoprecipitation and Western blotting}

At confluence, FLSs were harvested with trypsin-EDTA, pelleted, and resuspended in HAM-F12 without FCS. FLSs were incubated with adrenomedullin for 1 hour, and $10^{5}$ cells were seeded in triplicate for 2 hours. After incubation, cell proteins were extracted in lysis buffer. After centrifugation, the protein content of the supernatants was determined by using the Pierce protein assay. For immunoprecipitation (IP), $1 \mu \mathrm{g}$ of specific anti-talin antibody (Santa-Cruz) was incubated overnight at $4^{\circ} \mathrm{C}$ in a rotating device with Dynabeads Protein G (Dynal Biotech, Invitrogen) and 100- $\mu$ g aliquots of protein lysates. The magnetic beads were placed on a magnet, washed 3 times, suspended in lysis buffer and $4 \times$ running buffer (40\% glycerol, 8\% SDS, $0.250 M$ Tris (pH 6.8), and 0.8 $\mathrm{mg}$ bromophenol blue), and denatured for 5 minutes at $95^{\circ} \mathrm{C}$. The magnetic beads were placed on a magnet, and the denatured proteins were retained in $100 \mu \mathrm{l}$ lysis buffer, whereas the beads were discarded. Aliquots $(30 \mu \mathrm{l})$ were then subjected to electrophoresis resolved on 4-20\% SDS-PAGE gel (Bio-Rad) and transferred onto Hybond polyvinylidene difluoride membrane (Amersham Biosciences). The membranes were incubated for 1 hour with $1 \times$ blocking buffer and then reacted overnight with anti-talin antibody diluted 1:500 in blocking solution. The membranes were washed and incubated with the appropriate peroxidase-coupled secondary antibody. The signal was visualized by using a chemiluminescence detection system (Bio-Rad).

\section{Statistical analysis}

The data are reported as mean \pm SEM for adhesion experiments (at least three separate experiments with different donors). Groups were compared by using ANOVA and post hoc tests (Fisher test). All values are normalized for the control value. $P$ values less than 0.05 were considered significant.

\section{Results}

Adrenomedullin increases rheumatoid FLS adhesion to extracellular matrix proteins

RA-FLSs were treated with $10^{-7} \mathrm{M}$ adrenomedullin for 1 hour and studied in a 2-hour adhesion assay, as described earlier. The $10^{-7} \mathrm{M}$ adrenomedullin significantly enhanced RA-FLS adhesion to all three ECM proteins (Figure 1a), with a 2.39-, 2.25-, and 1.65-fold increase for vitronectin, fibronectin, and Coll.I, respectively (all with $P<0.0001$ ). No effect was seen with the negative controls (BSA and polylysin). These results suggest that adrenomedullin may specifically affect adhesion to FLS integrins, which are receptors of ECM proteins.

We evaluated RA-FLS adhesion after exposure to various adrenomedullin concentrations. The adhesionenhancing effect increased in a dose-dependent manner: 
(a)
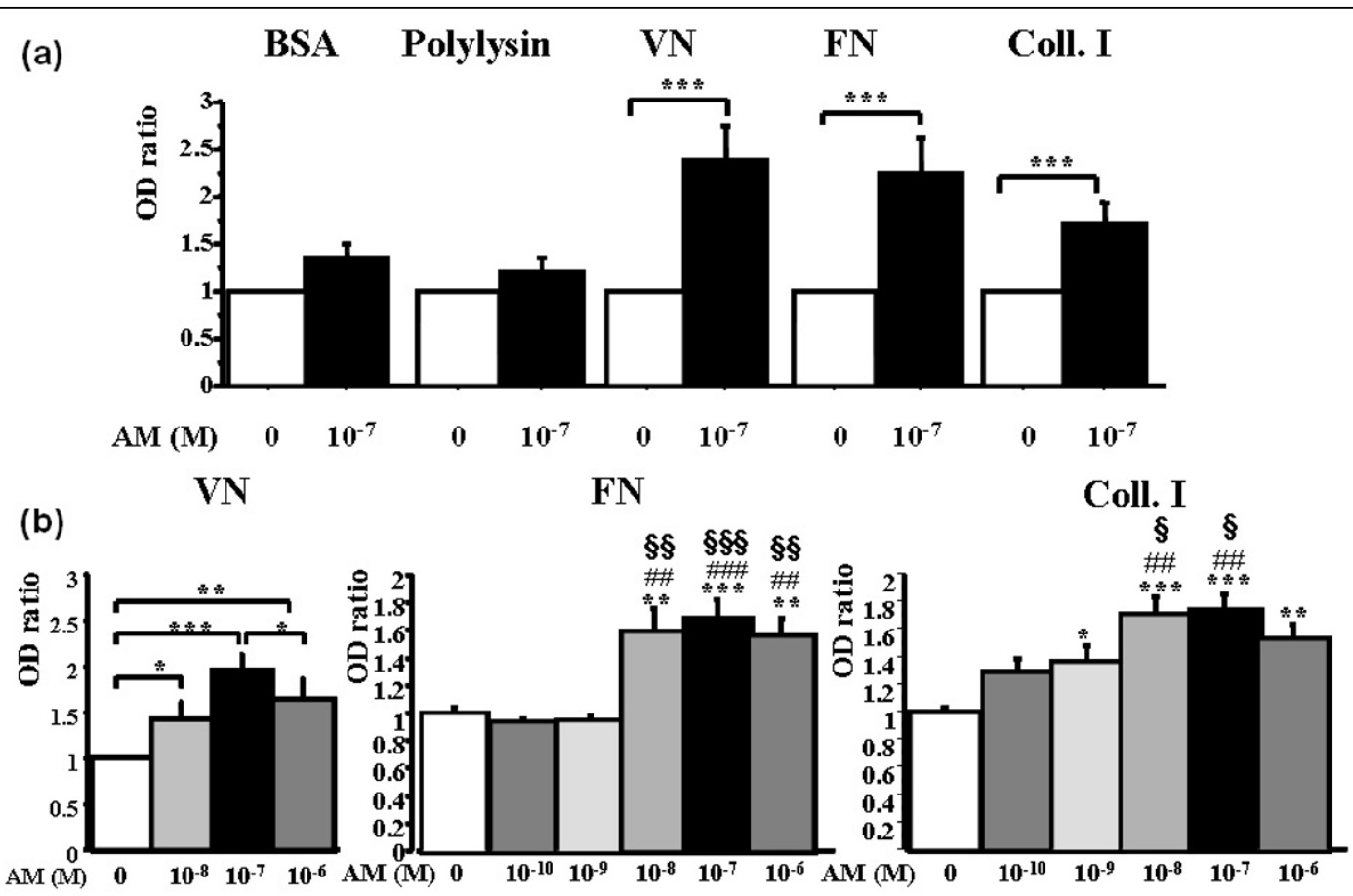

(c)

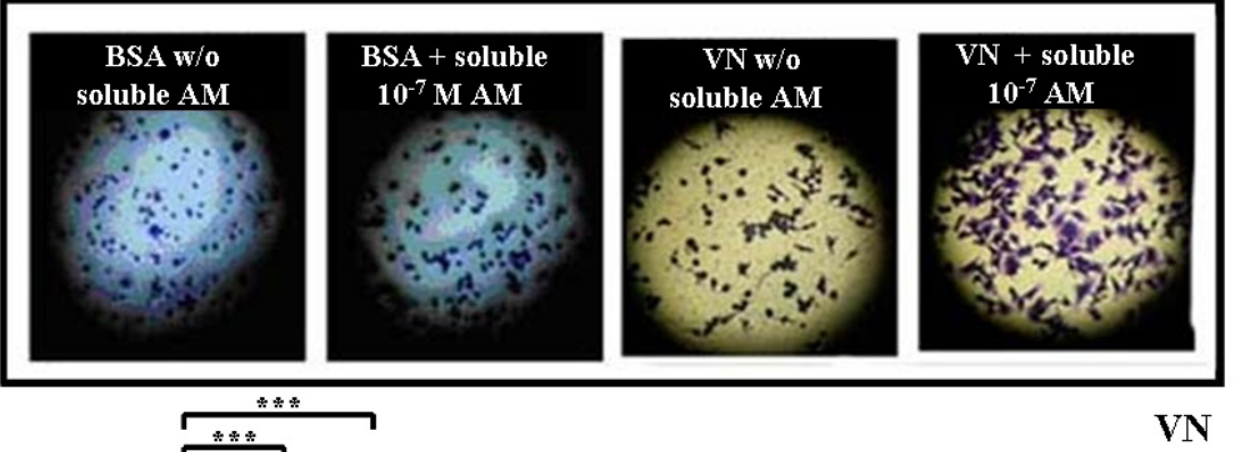

(d)
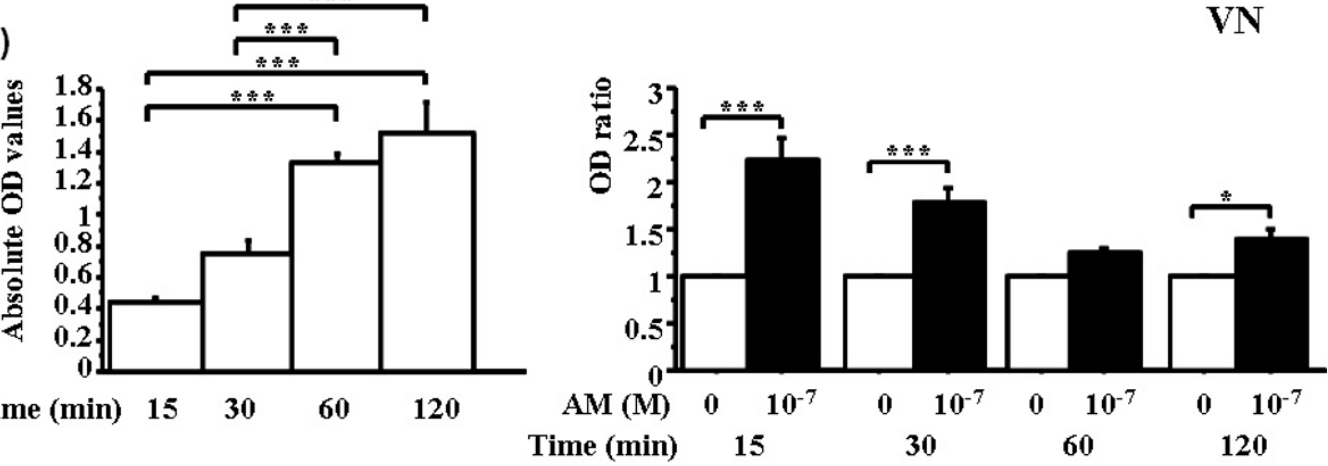

Figure 1 Adrenomedullin significantly and dose-dependently increases the adhesion of RA-FLSs to vitronectin, fibronectin, and type I collagen. RA-FLSs are resuspended in HAM-F12 without fetal calf serum and incubated for 1 hour with adrenomedullin (AM) at the indicated concentrations. Then $10^{5}$ cells with or without adrenomedullin are seeded on 96-well plates previously coated overnight with the extracellular matrix proteins, bovine serum albumin (BSA), or polylysin. After 2-hour adhesion, nonadherent cells are removed, and the remaining RA-FLSs are stained with violet crystal for 15 minutes. The plates are washed, and the cells are lysed. Adherent cells are quantified by measuring absorbance at $550 \mathrm{~nm}$ with a spectrophotometer. (a) Effect of AM on RA-FLS adhesion to different surfaces. (b) The effect of AM is dose dependent. (c) Phase-contrast microscopy photographs demonstrating adhesion of RA-FLSs to BSA (negative control) and vitronectin with or without $10^{-7} \mathrm{M}$ AM. (d) Time course of RA-FLSs adhesion to vitronectin under basal conditions (left panel) and with AM (right panel). Bars indicate mean \pm SEM. ${ }^{*} P<0.05$; ${ }^{* *} P<0.01$; ${ }^{* * *} P<0.0001$ versus control; ${ }^{\# \#} P<0.01$ and ${ }^{\# \# \#} P<0.0001$ versus $10^{-10} \mathrm{M} \mathrm{AM}$; and, ${ }^{\S \S} P<0.01$ and ${ }^{\S \S \S} P<0.0001$ versus $10^{-9}$ M AM. Results are given as the ratio of optical density (OD) in each condition over control OD without AM and reported as mean \pm SEM of three experiments (three different donors) performed in quadruplicate. 
1.41-fold with $10^{-8} \mathrm{M}(P=0.04)$; twofold with $10^{-7} \mathrm{M}$ $(P<0.0001)$ of adrenomedullin; 1.6 -fold at $10^{-8} M(P=$ $0.0001)$; and 1.7 -fold at $10^{-7} M(P<0.0001)$ on vitronectin and fibronectin, respectively (Figure $1 \mathrm{~b}$, middle panel). RA-FLS adhesion to Coll.I was dose-dependently increased by 1.4-, 1.7-, 1.8-, and 1.5-fold; $P=0.02, P<$ $0.0001, P<0.0001$, and $P=0.005$ with $10^{-9} M$ to $10^{-6}$ $M$ AM, respectively (Figure $1 \mathrm{~b}$, right panel). RA-FLSs exposed to adrenomedullin exhibited a spread-out shape on vitronectin after 2 hours, whereas the cells remained round on BSA (Figure 1c); no cell-to-cell adhesion was observed at higher-power field (not shown).

A time-course experiment was designed by using different incubation periods $(15,30,60$, and 120 minutes) with vitronectin only. Spontaneous RA-FLSs adhesion increased gradually with time from 0.43 OD at 15 minutes to $1.52 \mathrm{OD}$ at 2 hours (Figure 1d, i). By contrast, the effect of adrenomedullin on RA-FLSs adhesion was already maximal after 15 minutes $(2.2$-fold increase; $P<$ $0.0001)$. Nevertheless, this effect remained significant (1.4-fold increase, $P=0.02$ ) after 2 hours (Figure $1 d$, ii). Furthermore, after 2 hours, adrenomedullin-stimulated RA-FLSs had a typical spread-out fibroblast-like shape, contrasting with the round, loosely bound shape seen after 15 minutes. In subsequent experiments, we used the 2-hour period associated with firmer attachment.

\section{The adrenomedullin effect is specific of rheumatoid FLSs adhesion}

Given previous evidence that RA-FLSs expressed more adrenomedullin and adrenomedullin receptors (CLR/ RAMP-2 and CLR/RAMP-3) than did OA-FLS [10], we compared the effect of adrenomedullin on RA-FLSs and OA-FLSs. After 2 hours, basal adhesion to all three ECM proteins was not significantly different between RA-FLSs and OA-FLSs (Figure 2a). Adrenomedullin significantly increased RA-FLSs adhesion $(P<0.0001$ for all comparisons) but had no effect on OA-FLSs adhesion (Figure 2b). This constitutes the first evidence that the adhesion-enhancing effect of adrenomedullin is specific of RA-FLSs, at least in vitro.

The adhesion-enhancing effect of adrenomedullin is mediated by the adrenomedullin receptor CLR/RAMP

To investigate the role of adrenomedullin and its receptors in RA-FLSs adhesion, we preincubated the cells with (22-52)adrenomedullin, a specific antagonist of adrenomedullin receptors [10]. Without exogenous adrenomedullin, (22-52)adrenomedullin had no effect on RA-FLS adhesion as compared with control, even at (22-52)adrenomedullin highest concentration $\left(10^{-6} \mathrm{M}\right)$ (decrease by $20 \% ; P=0.08$ ) (Figure 3a). Adrenomedullin alone $\left(10^{-7} \mathrm{M}\right)$ significantly increased RA-FLSs adhesion (1.4-fold; $P=0.009$ ). This increase was significantly and dose-dependently inhibited by (22-52)adrenomedullin (decrease by $26 \%, 46 \%, 35 \%, 38 \%$, and $71 \% ; P=0.02$; $P=0.0002 ; P=0.0004 ; P=0.0002 ;$ and $P<0.0001$ with $10^{-10}, 10^{-9}, 10^{-8}, 10^{-7}$, and $10^{-6} \mathrm{M}$, respectively) (Figure 3a).

To confirm further the role for the adrenomedullin receptor and downstream signaling molecules, we used the pharmacologic PKA inhibitor H-89. Basal RA-FLS adhesion was significantly and dose-dependently decreased by H-89 (0.51-fold to 0.66-fold; $P=0.005)$ (Figure 3b). Moreover, adrenomedullin-enhanced RAFLSs adhesion (1.4-fold; $P=0.05)$ was significantly decreased by H-89 (0.36-fold to 0.6-fold; $P=0.002)$.

Finally, RAMP-2 siRNA enabled us to inhibit the AM co-receptor because it inhibited AM-induced adhesion by $48 \%, 62 \%$, and $72 \%(P<0.0001)$ with 5,10 , and $20 \mathrm{n} M$ RAMP-2 siRNA, respectively (Figure 3c).

\section{Adrenomedullin-enhanced rheumatoid FLSs adhesion is linked to integrin activation}

The specific and early effect of adrenomedullin on RAFLS adhesion to ECM proteins suggested activation of latent adhesion molecules. Therefore, we evaluated the role of integrins in FLSs adhesion. RGD peptide (an integrin competitor) inhibited basal and AM-stimulated RA-FLSs adhesion in a dose-dependent manner, whereas the scrambled peptide had no effect (Figure 4a).

We then evaluated the effect of adrenomedullin on integrin activation. A number of monoclonal antibodies recognize "activation" epitopes (extracellular portions of the integrin molecule that are present only when its ligand is bound). We then used HUTS-21 and AK-7, which specifically recognize the activated $\beta_{1}[21,22]$ and $\alpha_{2}$ integrin subunits, respectively. Adrenomedullin significantly increased the expression of both activated $\alpha_{2}$ (1.7-fold; $P=0.02$ ) and $\beta_{1}$ subunits $(1.5$-fold; $P=0.05$ ) (Figure $4 b, c$ ). Co-localization of the activated $\alpha_{2}$ and $\beta_{1}$ integrins was visible on the merged view (Figure $4 \mathrm{~b}$, right panel).

Moreover, we tested the hypothesis that adrenomedullin enhanced the interaction of talin with the $\beta_{1}$ subunit, thereby causing integrin activation. The $\beta_{1}$ subunit coimmunoprecipitated with talin, confirming that the two proteins are associated in a complex. Immunoblotting showed that adrenomedullin increased the talin- $\beta_{1}$ interaction (Figure 4d).

\section{The receptor antagonist (22-52)adrenomedullin inhibits adrenomedullin-related integrin activation}

Because adrenomedullin exerted its effects on RA-FLS through the CLR-RAMP receptor, we pretreated RAFLSs with $10^{-6} M$ (22-52)adrenomedullin, for 30 minutes, before adding $10^{-7} \mathrm{M}$ adrenomedullin (Figure 5). After 2-hour adhesion, $10^{-7} \mathrm{M}$ adrenomedullin significantly 


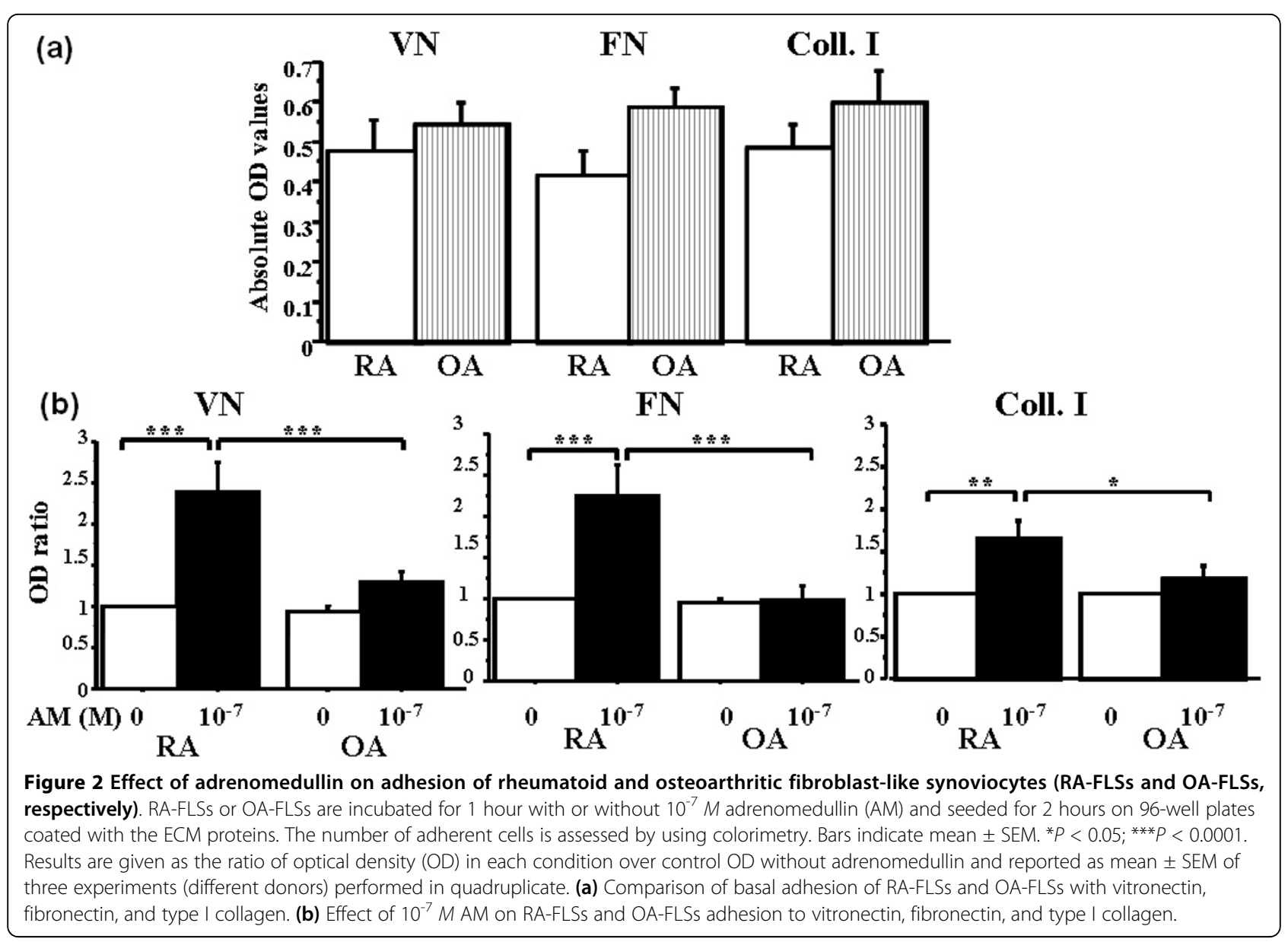

increased the expression of the $\alpha_{2}$ and $\beta_{1}$ subunits, 1.7fold and 1.4-fold, respectively, compared with controls. The (22-52)adrenomedullin significantly decreased AMstimulated $\alpha_{2}$ (Figure 5a) and $\beta_{1}$ (Figure 5b) subunits expression to control level. However, (22-52)adrenomedullin alone had no effect on activated integrin expression, compared with control RA-FLSs.

\section{Discussion}

This study provides the first evidence that adrenomedullin increases RA-FLS-integrin-dependent adhesion to several cartilage and bone ECM proteins by activating integrins, or at least their $\alpha_{2}$ and $\beta_{1}$ subunits (Figure 6). Of note, this effect was observed only with RA-FLSs and not with OA-FLSs. Integrin activation was mediated by the adrenomedullin receptors CLR/RAMP, because it was inhibited by the receptor antagonist (22-52)AM, by inhibition of PKA, a downstream signaling molecule, and by inhibition of RAMP-2 by siRNA. Moreover, we obtained indirect evidence of integrin activation through a talin-dependent pathway.

Adrenomedullin increased RA-FLSs adhesion to the ECM proteins vitronectin, fibronectin, and Coll.I, which are abundant in the rheumatoid pannus. Increased levels of fibronectin have been found in rheumatoid synovial tissues [23-25]. Vitronectin was increased in the synovial lining layer from both OA and RA tissues, compared with normal tissues [26]. The expression of several integrin-receptor subunits is also increased in situ. Rheumatoid synovial tissues express high levels of the $\alpha_{1}$ to $\alpha_{6}$ subunits, and of the $\beta_{1}, \beta_{3}$, and $\beta_{4}$ subunits, but low levels of the $\alpha_{\mathrm{v}}$ subunit $[7,27,28]$. The overexpressed integrins include $\alpha_{5} \beta_{1}$ and $\alpha_{v} \beta_{3}$ (the vitronectin receptor) and $\alpha_{2} \beta_{1}$ (the Coll.I receptor). Coll.I accounts for $90 \%$ of the organic matrix of mineralized bone [29], and RA is characterized by bone invasion and erosion [30], a process preceded by attachment of RA-FLSs to the articular cartilage [31]. For these reasons, we selected fibronectin, vitronectin, and Coll.I for our study of RA-FLS adhesion.

Few studies have compared OA-FLSs and RA-FLSs adhesion to cartilage and bone ECM proteins [32]. Schedel et al. [32] showed that OA-FLSs and RA-FLSs adhered more strongly to types I, II, and VI collagens than to BSA, with no difference between OA and RA cells. These results are consistent with our finding that basal adhesion to Coll. 
(a)

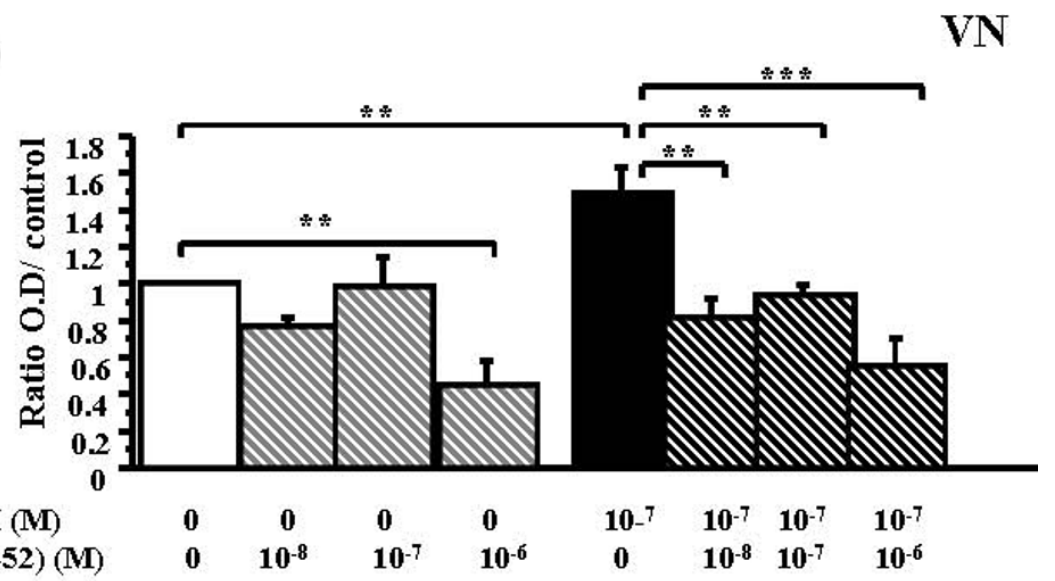

(b)

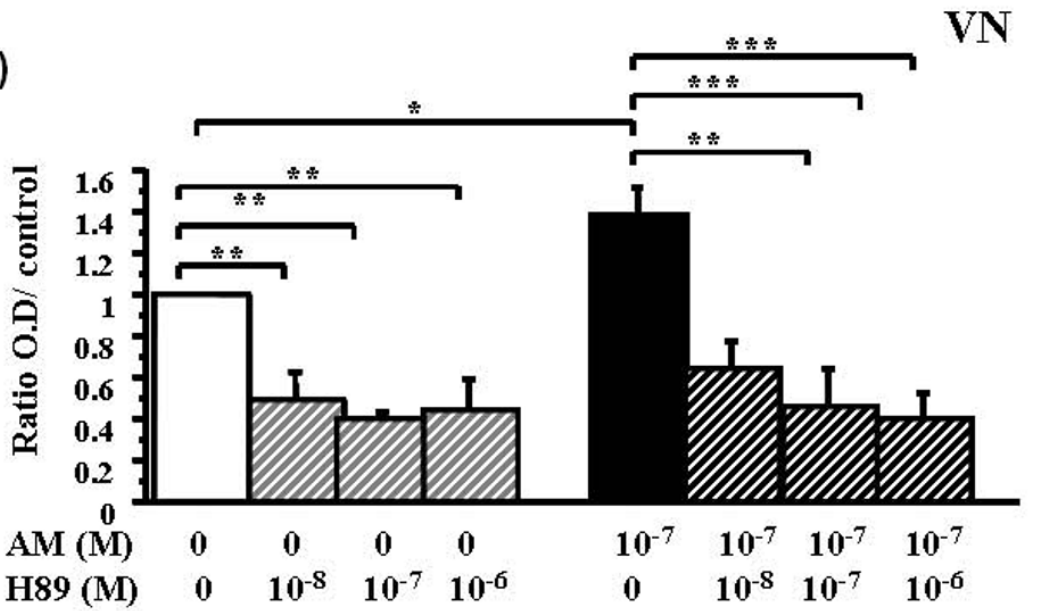

(c)

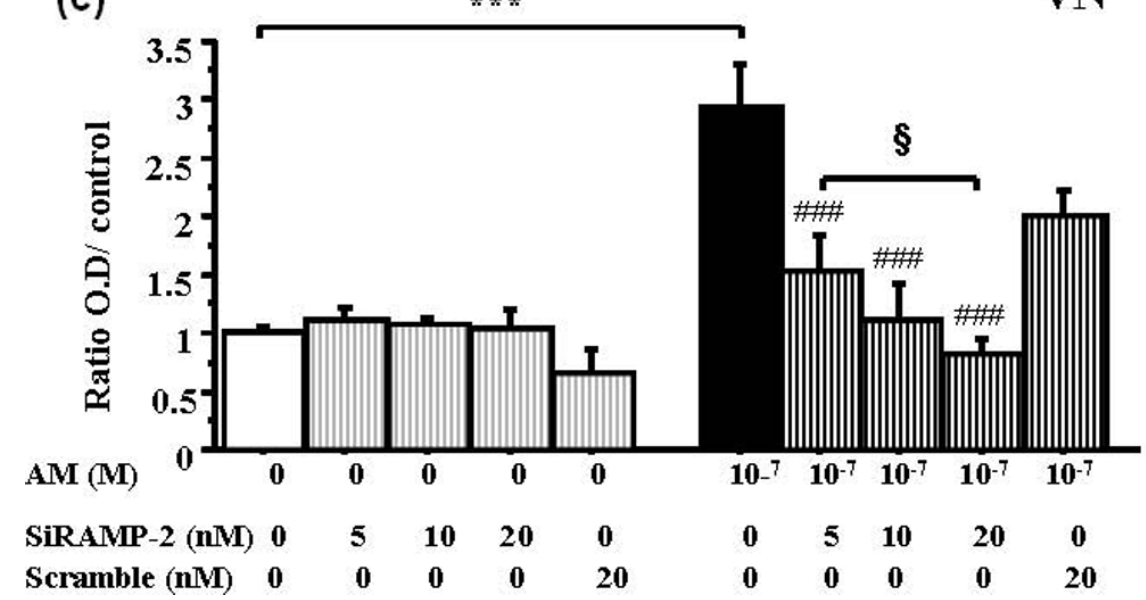

Figure 3 Adrenomedullin exerts its action on RA fibroblast adhesion through CLR/RAMP receptors. RA-FLSs were incubated for 30 minutes with various concentrations of (22-52)AM, or H-89, or for 24 hours with siRNA-RAMP-2 and then with or without soluble

adrenomedullin (AM) for 1 hour. (22-52)AM, H-89, and siRNA RAMP-2 inhibited the adhesion-enhancing effect of AM. Bars indicate mean \pm SEM. ${ }^{* * *} P<0.0001$; \#\#\# $P<0.0001$ versus $10^{-7} \mathrm{M} \mathrm{AM}$, and ${ }^{\S} P<0.05$. Results are given as the ratio of OD in each condition over control OD without AM and reported as mean \pm SEM of two experiments (different donors) performed in quadruplicate. (a) Dose-dependent effect of (22-52)AM on

basal and AM-stimulated RA-FLSs adhesion. (b) Dose-dependent effect of H-89 on basal and AM-stimulated RA-FLSs adhesion in each condition over OD of control. (c) Dose-dependent effect of siRNA RAMP-2 on AM-stimulated RA-FLSs adhesion in each condition over OD of control. 
(a)

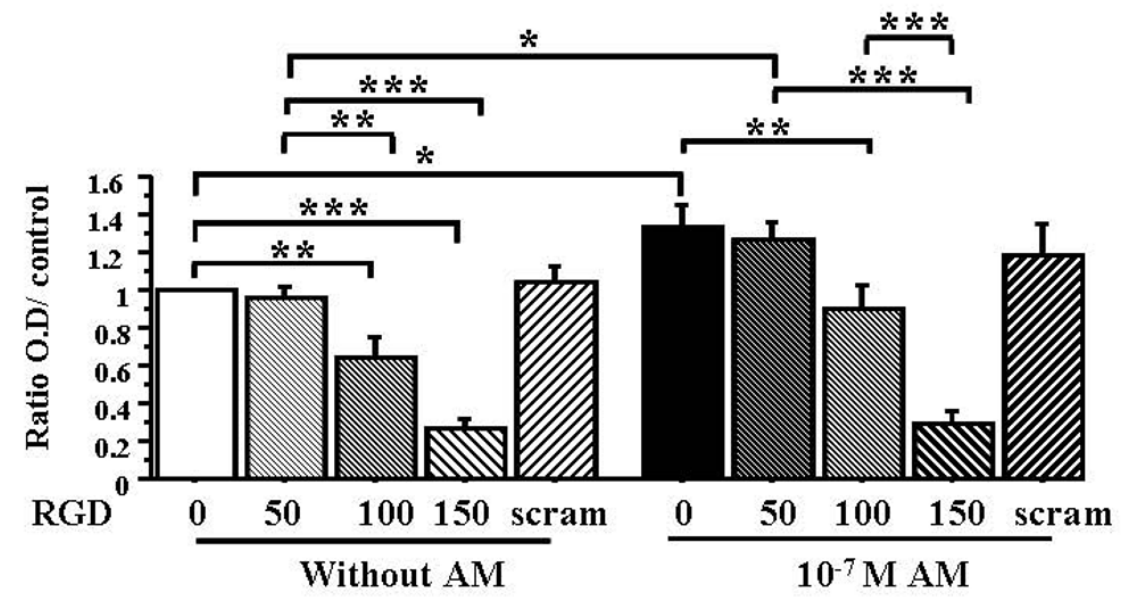

(b)

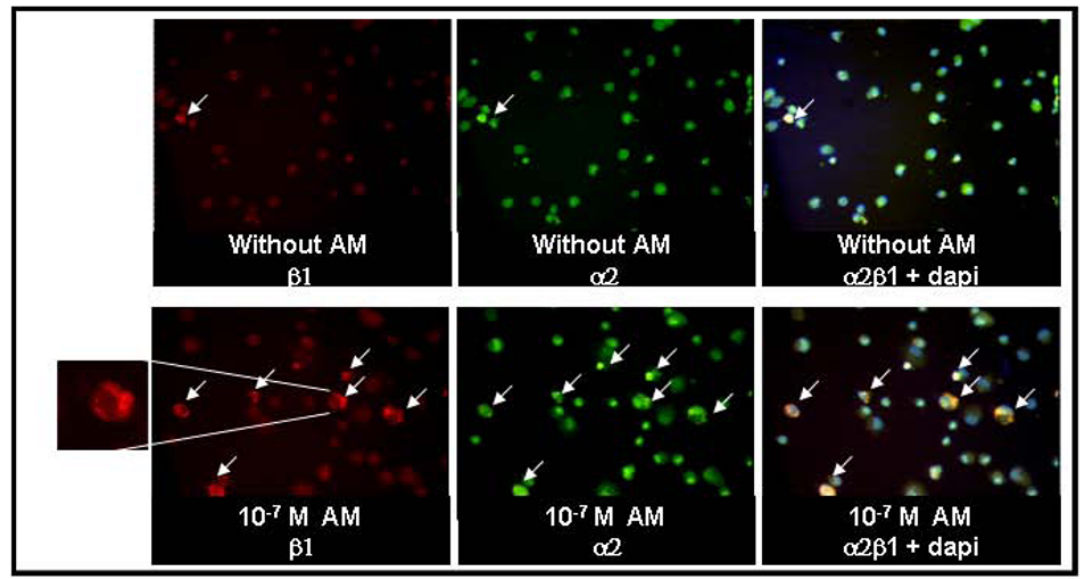

(c)

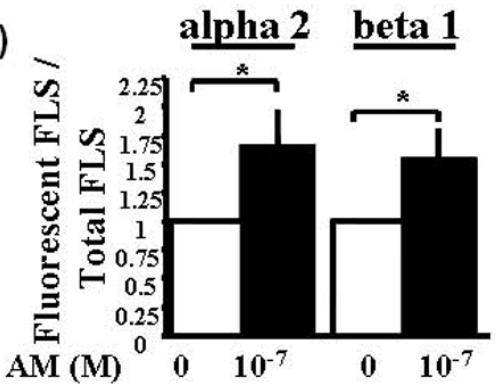

merge

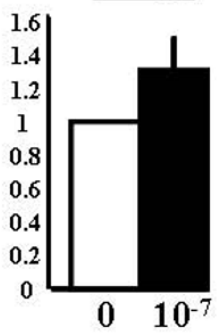

(d)

IP: Talin

WB: Anti- $\beta 1$

$\beta 1$

Talin-1

$\mathrm{AM}(\mathrm{M}) \quad 010^{-7}$

Figure 4 Adrenomedullin significantly increases cell-surface expression of activated $\alpha_{2}$ and $\beta_{1}$ integrins by rheumatoid fibroblast-like synoviocytes (RA-FLSs). RA-FLSs were incubated with $10^{-7} \mathrm{M}$ adrenomedullin (AM), or without AM as a control, for 1 hour. Bars indicate mean \pm SEM. ${ }^{*} P<0.05 ;{ }^{* *} P<0.01 ;{ }^{* *} P<0.0001$. Inhibition adhesion study was done with RGD peptides and scrambled peptide for 30 minutes before AM stimulation. A fluorescence microscope was used for visualization of three sections and image capture. The mean ratio of fluorescent cells from these three sections was calculated as the ratio of the number of fluorescent cells over total cells counted by DAPI staining. Results are given as the ratio of fluorescent cells over control cells without AM and reported as the mean \pm SEM of three experiments (three different donors) performed in triplicate. For IP, cell lysates from nonstimulated and AM-stimulated RA-FLSs were immunoprecipitated with anti-talin and then immunoreacted with anti- $\beta_{1}$ with Western blot analysis (The figure is representative of two experiments done with two different RA-FLSs). (a) Dose-dependent inhibition of FLSs adhesion by using RGD peptides. Left panel, basal adhesion; right panel, AM stimulation. (b) Observation with fluorescence microscopy of the distribution of activated $\alpha_{2}$ and $\beta_{1}$ integrin expression in RA-FLSs with or without $10^{-7} \mathrm{M} \mathrm{AM}$. Insert shows rim pattern or cytoplasmic membrane expression of activated integrin. (c) Effect of $10^{-7} \mathrm{M}$ adrenomedullin on the number of RA-FLSs expressing activated $\alpha_{2}$ and $\beta_{1}$ integrins. (d) IP: Effect of $10^{-7} \mathrm{M}$ AM on the talin- $\beta_{1}$ integrin interaction. 
(a)

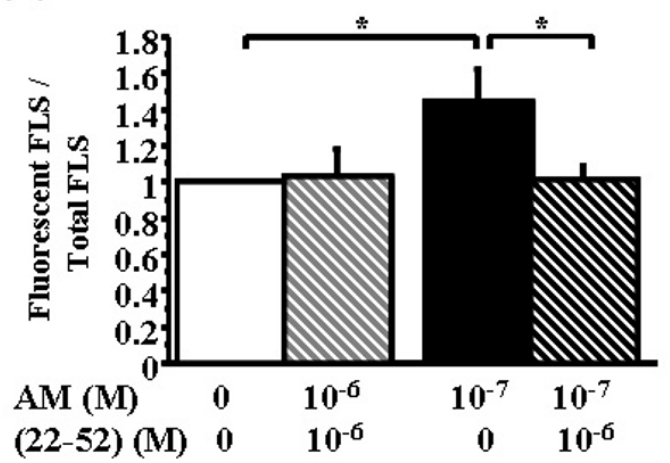

(b)

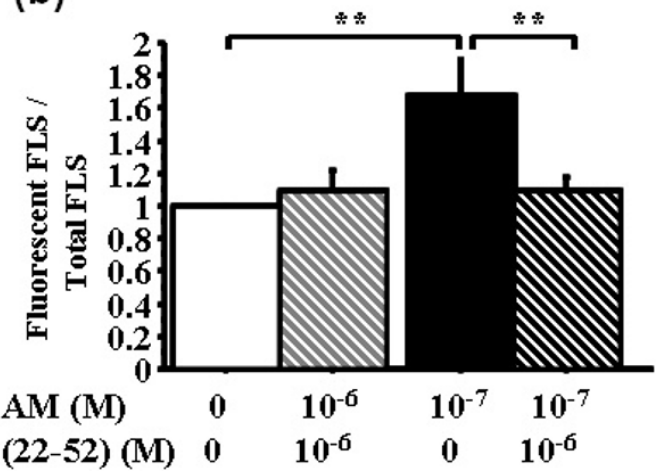

Figure 5 (22-52)AM inhibits adrenomedullin-induced activation of $\alpha_{2}$ and $\beta_{1}$ integrins on rheumatoid fibroblast-like synoviocytes (RAFLSs). RA-FLSs were incubated for 30 minutes with various concentrations of (22-52)adrenomedullin (AM) or H-89 and then with or without soluble AM for 1 hour. Bars indicate mean \pm SEM. ${ }^{*} P<0.05 ;{ }^{*} P<0.01 ;{ }^{* *} P<0.0001$. A fluorescence microscope was used for visualization of three sections and image capture. The mean ratio of fluorescent cells from these three sections was calculated as the ratio of the number of fluorescent cells over total cells counted with DAPI staining. Results are given as the ratio of fluorescent cells over control cells without AM and reported as the mean \pm SEM of three experiments (three different donors) performed in triplicate. (a) Mean fluorescence ratio of activated $\alpha_{2^{-}}$ subunit expression. (b) Mean fluorescence ratio of activated $\beta_{1}$-subunit expression.

I was not significantly different between RA-FLSs and OAFLSs. Rinaldi et al. [7] showed that isolated RA-FLSs were significantly more adherent than normal FLSs to fibronectin, but also to other ECM proteins such as laminin and tenascin, a protein involved in RA synovium remodeling. However, no previous studies compared RA-FLSs and OA-FLSs regarding basal adhesion to vitronectin and fibronectin; we found no difference between RA and OA cells. We cannot assume a complete specificity of the adrenomedullin effect in RA because we have not tested other FLSs derived from psoriatic arthritis, as an example.

We found that adrenomedullin specifically increased RA-FLS adhesion to ECM proteins but had no effect on OA-FLS adhesion. This difference may be ascribable to

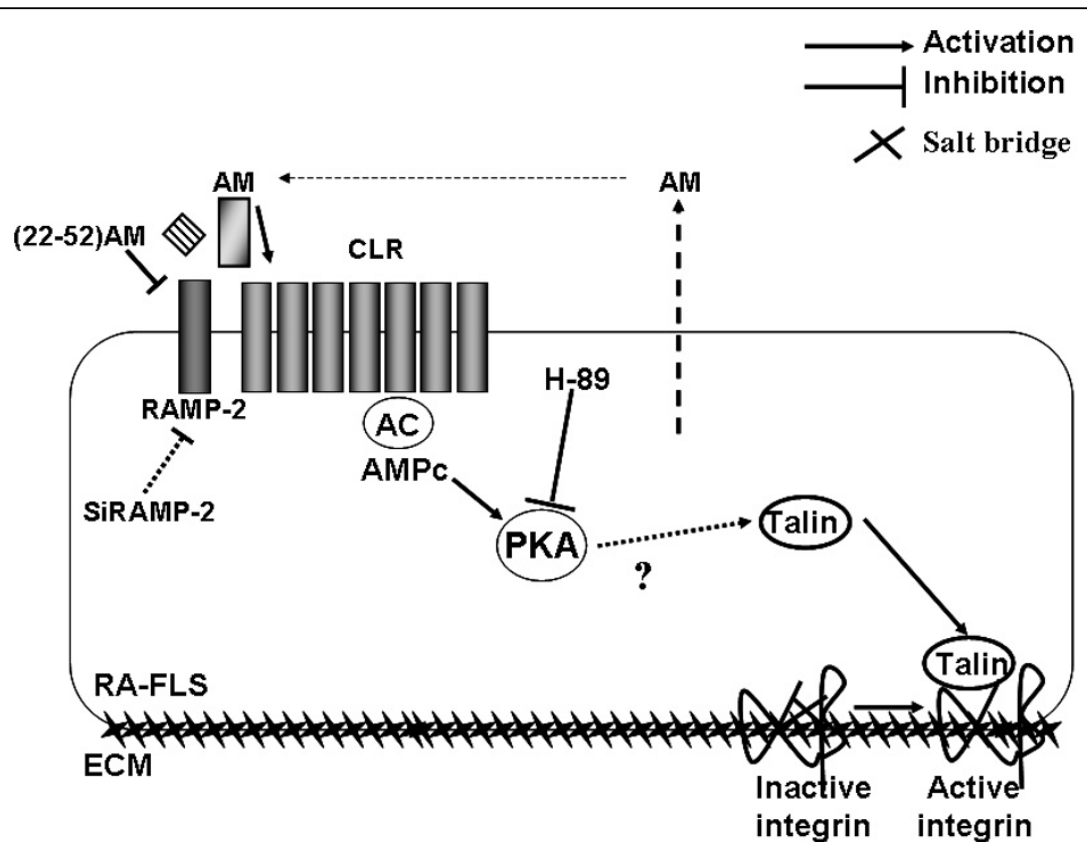

Figure 6 Model of adrenomedullin-induced regulation of rheumatoid fibroblast-like synoviocyte (RA-FLS) adhesion by the CLR-RAMP/ PKA pathway. Adrenomedullin (AM) activates RA-FLS adhesion to the extracellular matrix proteins vitronectin, fibronectin, and type I collagen. The AM-receptor antagonist (22-52)AM and silencing of RAMP-2 inhibited AM-induced RA-FLS adhesion of CLR/RAMP results in activation of PKA, as assessed by its inhibition by $\mathrm{H}-89$. AM triggers a talin- $\beta_{1}$ chain interaction, disrupting the salt bridge between the $\alpha$ and $\beta$ subunits and thereby activating the integrins, explaining the increase in RA-FLS adhesion. 
the stronger expression of adrenomedullin receptor (CLR/RAMP2) mRNA and proteins by RA-FLSs than by OA-FLSs [10]. Moreover, our inhibition experiments using an adrenomedullin-receptor antagonist, an inhibitor of PKA, and one RAMP-2 siRNA confirmed the role for adrenomedullin receptors. It should be mentioned that no in vitro receptor binding kinetics compared (2252)adrenomedullin with adrenomedullin.

Our findings suggest that the effect of adrenomedullin may be specific for adhesion molecules, such as integrins. The effect of adrenomedullin on RA-FLSs adhesion was already at its peak after 15 minutes, when adhesion was loose, whereas after 2 hours, the RA-FLSs exhibited the typical spreadout fibroblast-like appearance. In our attempt to demonstrate early adhesion-molecule expression, we selected integrins, because these are presynthesized in an inactive form and expressed at the membrane cell surface, and they are natural receptors for ECM proteins. With the specific antibodies AK7 and HUTS-21, we found that adrenomedullin induced integrin activation through a mechanism involving the adrenomedullin receptors. Integrin-mediated cell adhesion has been shown to depend on CAMP/PKA [33].

We studied only the $\alpha_{2}$ and $\beta_{1}$ integrin subunits, which are involved in cell adhesion, not only to Coll.I and fibronectin, but also to other ECM molecules of interest, such as type II collagen [7]. The signaling pathways leading from CLR-AC-PKA activation to integrin activation are unknown. However, we hypothesized that talin, a major integrin activator, was activated by adrenomedullin. As siRNA would inhibit not only adrenomedullin-stimulated adhesion, but also basal adhesion, we chose talin IP followed by integrin $\beta_{1}$ immunoblotting to investigate the interaction of the two proteins with adrenomedullin. We found that adrenomedullin stimulated integrin activation by increasing this talin- $\beta_{1}$ interaction. Moreover, by using the adrenomedullin-receptor antagonist (22-52) $\mathrm{AM}$, we were able to confirm the role for adrenomedullin in $\alpha_{2}$ and $\beta_{1}$ integrin activation.

Previous studies have established that adrenomedullin activates adhesion molecules in other cell types. With HUVECs, adrenomedullin induces cell-surface expression of E-selectin, vascular cell adhesion molecule (VCAM-1), and ICAM-1 [17], through adenylate cyclase activation. These studies investigated only the effect of adrenomedullin on adhesion-molecule expression, whereas we used a reproducible functional adhesion assay to study FLSs adhesion in addition to integrin activation.

Adrenomedullin also increased capillary cell activation and neoangiogenesis in various animal models of tissue repair or tumor growth [34,35]. Angiogenesis occurs in the rheumatoid pannus and is an early event in collageninduced arthritis [36]. Adrenomedullin [37] and (22-52) adrenomedullin [38] can stimulate or inhibit the spread of metastases in vivo, respectively. Cell adhesion is the first event in a multistep process and is followed by migration and invasion in angiogenesis, tumor growth, and invasiveness. We have obtained preliminary evidence supporting a role for adrenomedullin in increasing RAFLSs migration in a two-dimensional system (Asensio and Ah Kioon, unpublished data). Overall, adrenomedullin may contribute to cell adhesion, migration, proliferation, and reduced apoptosis. These events are involved not only in pannus progression but also in tumor development, indicating a new role for adrenomedullin.

\section{Conclusions}

In this work, we showed that soluble adrenomedullin increases RA-FLSs adhesion to various ECM proteins expressed in synovial tissue, cartilage, or bone. This effect is mediated by the adrenomedullin receptor CLR, and it does not occur with OA-FLSs, which express fewer adrenomedullin receptors [10]. This adrenomedullin-dependent RA-FLSs adhesion is ascribable to activation of the talin- $\beta_{1}$ interaction followed by integrin activation (Figure 6). Thus, adrenomedullin may participate in the regulation of RA-FLSs and therefore to some extent in the pathogenesis of RA.

\section{Abbreviations}

AC: adenylate cyclase; BSA: bovine serum albumin; CLR: calcitonin receptorlike receptor; Coll.I: type I collagen; ECM: extracellular matrix; FCS: fetal calf serum; FITC: fluorescein isothiocyanate; FLS: fibroblast-like synoviocyte; HUVEC: human umbilical vein endothelial cell; ICAM: intercellular adhesion molecule; IP: immunoprecipitation; OA: osteoarthritis; PE: phycoerythrin; PFA: paraformaldehyde; PKA: protein kinase A; RA: rheumatoid arthritis; RAMP: receptor activity-modifying proteins; RT: room temperature; VCAM-1: vascular cell adhesion molecule.

\section{Acknowledgements}

We thank Dr Eric Roulot, MD, and Prof. Rémy Nizard, MD, PhD, for providing synovial tissues. Ah Kioon, MD, received doctoral grants from the Société Française de Rhumatologie (SFR), the Association Rhumatisme et Travail (ART), and the Association pour la Recherche en Pathologie Synoviale (ARPS). B Uzan received doctoral grants from the ART and ARPS. This study was funded by the INSERM, Paris-Diderot University, SFR, ART, and ARPS. Prof. F Lioté received unrestricted research grants from Wyeth and Abbott France. None of the funding sources had any role in designing the study; collecting, analyzing, or interpreting the data; writing the study report; or deciding to submit the study report for publication.

\section{Author details}

${ }^{1}$ INSERM UMR-S 606, Hôpital Lariboisière, Ambroise Paré Street, 75010 Paris, France. ${ }^{2}$ Paris-Diderot University, Thomas Mann Street, 75013 Paris, France. ${ }^{3}$ UFR Faculty of Medicine, Square Villemin, 75010 Paris, France.

\section{Authors' contributions}

MDAK was responsible for the conception and design, acquisition of data, analysis and interpretation of data, and drafting of the manuscript; CA, for acquisition of data and drafting of the manuscript; HKE, for conception and design, analysis and interpretation of data, and drafting of the manuscript; $\mathrm{BU}$, for acquisition of data, analysis and interpretation of data, and drafting of the manuscript; MCS, for analysis and interpretation of data and drafting of the manuscript; FL, for conception and design, analysis and interpretation 
of data, drafting of the manuscript, and supervision. All authors read and approved the final manuscript.

\section{Competing interests}

The authors declare that they have no competing interests.

Received: 25 November 2009 Revised: 23 July 2010

Accepted: 14 October 2010 Published: 14 October 2010

\section{References}

1. Pap T, Muller-Ladner U, Gay RE, Gay S: Fibroblast biology: role of synovia fibroblasts in the pathogenesis of rheumatoid arthritis. Arthritis Res 2000, 2:361-367.

2. Wang AZ, Wang JC, Fisher GW, Diamond HS: Interleukin-1beta-stimulated invasion of articular cartilage by rheumatoid synovial fibroblasts is inhibited by antibodies to specific integrin receptors and by collagenase inhibitors. Arthritis Rheum 1997, 40:1298-1307.

3. Mould AP, Humphries MJ: Regulation of integrin function through conformational complexity: not simply a knee-jerk reaction? Curr Opin Cell Biol 2004, 16:544-551.

4. Calderwood DA, Tai V, Di Paolo G, De Camilli P, Ginsberg MH: Competition for talin results in trans-dominant inhibition of integrin activation. J Biol Chem 2004, 279:28889-28895.

5. Moser M, Legate KR, Zent R, Fassler R: The tail of integrins, talin, and kindlins. Science 2009, 324:895-899.

6. Ginsberg MH, Partridge A, Shattil SJ: Integrin regulation. Curr Opin Cell Biol 2005, 17:509-516.

7. Rinaldi N, Schwarz-Eywill M, Weis D, Leppelmann-Jansen P, Lukoschek M, Keilholz U, Barth TF: Increased expression of integrins on fibroblast-like synoviocytes from rheumatoid arthritis in vitro correlates with enhanced binding to extracellular matrix proteins. Ann Rheum Dis 1997, 56:45-51.

8. Beltowski J, Jamroz A: Adrenomedullin: what do we know 10 years since its discovery? Pol J Pharmacol 2004, 56:5-27.

9. Naot $D$, Cornish J: The role of peptides and receptors of the calcitonin family in the regulation of bone metabolism. Bone 2008, 43:813-818.

10. Uzan B, Ea HK, Launay JM, Garel JM, Champy R, Cressent M, Liote F: A critical role for adrenomedullin-calcitonin receptor-like receptor in regulating rheumatoid fibroblast-like synoviocyte apoptosis. J Immunol 2006, 176:5548-5558

11. Yudoh $\mathrm{K}$, Matsuno $\mathrm{H}$, Kimura $\mathrm{T}$ : Plasma adrenomedullin in rheumatoid arthritis compared with other rheumatic diseases. Arthritis Rheum 1999, 42:1297-1298.

12. Chosa E, Hamada H, Kitamura K, Eto T, Tajima N: Increased plasma and joint tissue adrenomedullin concentrations in patients with rheumatoid arthritis compared to those with osteoarthritis. J Rheumatol 2003, 30:2553-2556

13. Zudaire E, Martinez A, Cuttitta F: Adrenomedullin and cancer. Regul Pept 2003, 112:175-183

14. Horio T, Kohno M, Kano H, Ikeda M, Yasunari K, Yokokawa K, Minami M, Takeda T: Adrenomedullin as a novel antimigration factor of vascular smooth muscle cells. Circ Res 1995, 77:660-664.

15. Kim W, Moon SO, Sung MJ, Kim SH, Lee S, So JN, Park SK: Angiogenic role of adrenomedullin through activation of Akt, mitogen-activated protein kinase, and focal adhesion kinase in endothelial cells. FASEB J 2003, 17:1937-1939.

16. Nikitenko LL, Fox SB, Kehoe S, Rees MC, Bicknell R: Adrenomedullin and tumour angiogenesis. Br J Cancer 2006, 94:1-7.

17. Hagi-Pavli E, Farthing PM, Kapas S: Stimulation of adhesion molecule expression in human endothelial cells (HUVEC) by adrenomedullin and corticotrophin. Am J Physiol Cell Physiol 2004, 286:C239-C246.

18. Hagi-Pavli E, Farthing PM, Henshaw FN, Kapas S: Presentation of ICAM-1 protein at the cell surface of oral keratinocytes in the presence of adrenomedullin and corticotrophin. Cell Physiol Biochem 2005, 15:167-174.

19. Arnett FC, Edworthy SM, Bloch DA, McShane DJ, Fries JF, Cooper NS, Healey LA, Kaplan SR, Liang MH, Luthra HS, Medsger TA, Mitchell DM, Neustadt DH, Pinals RS, Schaller JG, Sharp JT, Wilder RL, Hunder GG: The American Rheumatism Association 1987 revised criteria for the classification of rheumatoid arthritis. Arthritis Rheum 1988, 31:315-324.

20. Liote F, Champy R, Moenner M, Boval-Boizard B, Badet J: Elevated angiogenin levels in synovial fluid from patients with inflammatory arthritis and secretion of angiogenin by cultured synovial fibroblasts. Clin Exp Immunol 2003, 132:163-168.

21. Luque A, Gomez M, Puzon W, Takada Y, Sanchez-Madrid F, Cabanas C: Activated conformations of very late activation integrins detected by a group of antibodies (HUTS) specific for a novel regulatory region (355425) of the common beta 1 chain. J Biol Chem 1996, 271:11067-11075.

22. Bazzoni G, Hemler ME: Are changes in integrin affinity and conformation overemphasized? Trends Biochem Sci 1998, 23:30-34.

23. Haynes BF, Hale LP, Patton KL, Martin ME, McCallum RM: Measurement of an adhesion molecule as an indicator of inflammatory disease activity: up-regulation of the receptor for hyaluronate (CD44) in rheumatoid arthritis. Arthritis Rheum 1991, 34:1434-1443.

24. Scott DL, Wainwright AC, Walton KW, Williamson N: Significance of fibronectin in rheumatoid arthritis and osteoarthrosis. Ann Rheum Dis 1981, 40:142-153.

25. Vartio T, Vaheri A, Von Essen R, Isomaki H, Stenman S: Fibronectin in synovial fluid and tissue in rheumatoid arthritis. Eur J Clin Invest 1981, 11:207-212.

26. Nikkari L, Haapasalmi K, Aho $H$, Torvinen A, Sheppard D, Larjava $H$, Heino J: Localization of the alpha $v$ subfamily of integrins and their putative ligands in synovial lining cell layer. J Rheumatol 1995, 22:16-23.

27. Nikkari $L$, Aho $H, Y l i-J a m a ~ T, ~ L a r j a v a ~ H$, Jalkanen $M$, Heino J: Expression of integrin family of cell adhesion receptors in rheumatoid synovium: alpha 6 integrin subunit in normal and hyperplastic synovial lining cell layer. Am J Pathol 1993, 142:1019-1027.

28. Ishikawa H, Hirata S, Nishibayashi Y, Imura S, Kubo H, Ohno O: The role of adhesion molecules in synovial pannus formation in rheumatoid arthritis. Clin Orthop Relat Res 1994, 297-303.

29. Deftos $L$ : Bone protein and peptide assays in the diagnosis and management of skeletal disease. Clin Chem 1991, 37:1143-1148.

30. Schett G: Cells of the synovium in rheumatoid arthritis: osteoclasts. Arthritis Res Ther 2007, 9:203.

31. Huber LC, Distler O, Tarner I, Gay RE, Gay S, Pap T: Synovial fibroblasts: key players in rheumatoid arthritis. Rheumatology (Oxford) 2006, 45:669-675.

32. Schedel J, Wenglen C, Distler O, Muller-Ladner U, Scholmerich J, Heinegard D, Krenn V: Differential adherence of osteoarthritis and rheumatoid arthritis synovial fibroblasts to cartilage and bone matrix proteins and its implication for osteoarthritis pathogenesis. Scand J Immunol 2004, 60:514-523.

33. Howe AK: Regulation of actin-based cell migration by cAMP/PKA. Biochim Biophys Acta 2004, 1692:159-174.

34. limuro S, Shindo T, Moriyama N, Amaki T, Niu P, Takeda N, Iwata H, Zhang $Y$, Ebihara A, Nagai R: Angiogenic effects of adrenomedullin in ischemia and tumor growth. Circ Res 2004, 95:415-423.

35. Fernandez-Sauze S, Delfino C, Mabrouk K, Dussert C, Chinot O, Martin PM, Grisoli F, Ouafik L, Boudouresque F: Effects of adrenomedullin on endothelial cells in the multistep process of angiogenesis: involvement of CRLR/RAMP2 and CRLR/RAMP3 receptors. Int J Cancer 2004, 108:797-804

36. Clavel G, Bessis N, Lemeiter D, Fardellone P, Mejjad O, Menard JF, Pouplin S, Boumier $P$, Vittecoq $O$, Le Loet $X$, Boissier MC: Angiogenesis markers (VEGF, soluble receptor of VEGF and angiopoietin-1) in very early arthritis and their association with inflammation and joint destruction. Clin Immunol 2007, 124:158-164.

37. Ouafik L, Sauze $S$, Boudouresque F, Chinot $O$, Delfino C, Fina F, Vuaroqueaux V Dussert C, Palmari J, Dufour H, Grisoli F, Casellas P, Brunner N, Martin PM: Neutralization of adrenomedullin inhibits the growth of human glioblastoma cell lines in vitro and suppresses tumor xenograft growth in vivo. Am J Pathol 2002, 160:1279-1292.

38. Ishikawa T, Chen J, Wang J, Okada F, Sugiyama T, Kobayashi T, Shindo M, Higashino F, Katoh H, Asaka M, Kondo T, Hosokawa M, Kobayashi M: Adrenomedullin antagonist suppresses in vivo growth of human pancreatic cancer cells in SCID mice by suppressing angiogenesis. Oncogene 2003, 22:1238-1242.

doi:10.1186/ar3160

Cite this article as: Ah Kioon et al:: Adrenomedullin increases fibroblastlike synoviocyte adhesion to extracellular matrix proteins by upregulating integrin activation. Arthritis Research \& Therapy 2010 12:R190. 